http://jmscr.igmpublication.org/home/

ISSN (e)-2347-176x ISSN (p) 2455-0450

crossref DOI: https://dx.doi.org/10.18535/jmscr/v7i7.157

Journal Of Medical Science And Clinical Research

\title{
Functional Outcome of Internal Fixation of Lisfranc Fractures
}

\author{
Authors \\ Vaisakh Vasant Kumar', Manoj Murungodiyil Kunjappan ${ }^{2}$ \\ ${ }^{1}$ Junior Resident, Department of Orthopaedics, Government Medical College, Thrissur, Kerala \\ ${ }^{2}$ Associate Professor, Department of Orthopaedics, Government Medical College, Thrissur, Kerala
}

\begin{abstract}
Background: The occurrence of Lisfranc fractures in our population is increasing with rise in road traffic accidents despite being a rare fracture to see. Diagnosis of these fractures is always a challenge to the treating orthopedician. Few studies have only been done in India on such fractures and that explains the need for research in treating these fractures.

Materials and Methods: This prospective observational study reports the functional outcome of 20 patients operated with internal fixation. 20 patients with Lisfranc fracture fitting for the inclusion criteria who came to Orthopaedic Department of Thrissur medical college between 1/1/2016 and 1/1/2017 were surgically treated with open reduction and internal fixation with transarticular screws. Partial weight bearing was started only after the onset of radiological union. They were followed up clinically and radiologically for six months. Functional outcome was assessed after 6 months using American Orthopaedic Foot and Ankle Society (AOFAS) score.

Results \& Discussion: In our study the mean age of males was $29.7(n=9)$ and females was $40.2(n=11)$. Equal distribution of cases in case of high energy and low energy injury was seen. Right foot was found to be involved in $60 \%$ of cases. Four cases had associated tendon injury and another eight cases had suffered other fractures of foot. Diabetes and hypertension were associated in 4 cases. Five patients had developed significant osteoarthritis following surgery. Average stay in hospital was 17 days. Average AOFAS score was 80.4. Excellent results were obtained for 4 cases (20\%) and good results for 11 cases (55\%).

Conclusion: Internal fixation is a good method for reducing and fixing Lisfranc fractures early to improve functional results. Early mobilization and proper follow up are also necessary for good functional outcome.
\end{abstract}

Keywords: Lisfranc fracture ;Internal fixation; Functional outcome; AOFAS score.

\section{Introduction}

Acute injuries to the tarsometatarsal (TMT) or Lisfranc joint are rare accounting for $0.1 \%$ to $0.4 \%$ of all fractures and dislocations ${ }^{[1]}$. Despite improvements in diagnosis, missed or overlooked injuries are common. Especially the isolated pure ligamentous TMT instability is misdiagnosed in up to $20 \%{ }^{[1]}$. Insufficient treatment can lead to painful secondary deformity and impaired function. While, non operative treatment has been linked to an increased incidence of secondary displacement and inferior functional outcome, primary open reduction and internal fixation has become the preferred method of treatment when there is structural ligamentous instability or fracture-dislocation ${ }^{[1]}$. Surgical reconstruction can not only reestablish normal gait biomechanics, but it also prevents secondary arthritis and improves functional outcome. 
The difficulty to diagnose this fracture also explains the difficulty to treat it.

Depending on the injury pattern the treatment combination also vary from simple kwire fixation to screw and plate combination. Moreover postoperative period is riddled with complications ranging from secondary osteoarthritis to implant failure.

\section{Materials and Methods}

The present study is a prospective descriptive study of 20 patients who sustained Lisfranc fracture-dislocation and were treated with internal fixation at Government Medical College, Thrissur from 01/01/2016 to 01/07/2017.

The inclusion criteria included all consenting patients in the age group of 20-70 years with clinically or radiologically proven Lisfranc fracture-dislocation treated by internal fixation.

The exclusion criteria included patients who were not fit for surgical treatment, with previous surgery in the fractured area,with previous musculoskeletal diseases or conditions, with head chest or abdominal trauma, patients who were not willing for take part in study and patients who were bedridden prior to fracture.

After proper history recording, clinical examination, radiological investigations preoperative work up and after obtaining informed written consent, patients were admitted for surgery. According to the Myerson's modified classification, fractures were classified into: Type A (homolateral), Type B1(Medial partial incongruity), TypeB2 (lateral partial incongruity), TypeC1 (partial divergent) and Type C2 (complete divergent).

For each surgery, the leading surgeon was a senior surgeon not below the rank of Assistant Professor, Dept. of Orthopedics GMCH. Thrissur. After attaining adequate anesthesia, patient was positioned supine with bolster under the knee for a plantigrade foot on a radioluscent table. Fracture was reduced under fluoroscopic guidance by closed manipulation. AP and lateral image were obtained and saved for reference. Standard methods of scrubbing, painting and draping were followed. A dorsal longitudinal incision from the mid diaphyseal region between 1 st and 2 nd metatarsals extending above over the interval between 1 st and $2^{\text {nd }}$ TMT joints is made ,deep dissection done and dorsalis pedis artery identified and retracted to one side along with the extensor hallucis longus tendon medially and extensor halluces brevis laterally. Capsule opened if not injured periosteal elevation done.

Fracture was reduced and alignment was checked under fluoroscopy. Fracture fixed along intercuneiform, medial cuneiform to base of 2 nd metatarsal and base of $1^{\text {st }}$ metatarsal to medial cuneiform with $3.5 \mathrm{~mm}$ cortical/cancellous screws after stabilizing using $1.8 \mathrm{~mm}$ Kwires. The 3rd, 4th and 5th TMT joints assessed under fluoroscope and if found to be unstable stabilized with $1.8 \mathrm{~mm}$ Kwires percutaneously or through another longitudinal incision along the 4th metatarsal. Fixation checked under fluroscope in anteroposterior, lateral and oblique views. After attaining hemostasis, a good washing was given with sterile normal saline. Skin closed in layers. Dressings given. Limb immobilized in below knee plaster slab with lower limb elevation. Length of incision, amount of blood lost, operation time and intraoperative findings were recorded.

Adequate analgesics were provided. IV third generation Cephalosporins were administered post operatively up to day 7. Dressings were changed on post op day 3,day 6 and staples were removed by post operative day 10 if healed. Patients were discharged with below knee cast applied for 3 weeks.

Patients were followed up regularly after 3 weeks, 6 weeks, 12weeks, and 6 months of discharge. During each visit, patients were examined for subjective symptoms and objective signs. AP and oblique plane X-ray radiograph of foot was taken and radiological signs of fracture union were assessed. If the fracture showed the onset of radiological union, the patient was allowed for weight bearing in walking below knee cast after removal of kwires. Later full weight bearing was 
allowed. Details of each visit were recorded in the proforma of each patient.

Functional outcome is evaluated using American Orthopaedic Foot and Ankle Society (AOFAS) score after 6 months of surgery during the follow up visit.

\section{Observations and Results}

In the present series the maximum age was 57 in females and 54 in case of males. The mean age in males being 29 and in females being 40. The number of females were 11 and males 9 in the present series.

The patients were scored on the basis of their pain and its relation to the activities of the patient. Most of the patient were pain free after 3 weeks.

Functional outcome was assessed using American Foot and Ankle Society Score (AOFAS) score and was the mean score was 80.4 with $20 \%$ having excellent score and 55\% having good score. Poor score was seen only in 2 cases.

Distribution of sample by criteria of age

\begin{tabular}{|l|c|c|}
\hline & Frequency & Percentage \\
\hline $20-30$ & 9 & 45 \\
\hline $30-40$ & 3 & 15 \\
\hline $40-50$ & 4 & 20 \\
\hline $50-60$ & 4 & 20 \\
\hline $60-70$ & 0 & 0 \\
\hline
\end{tabular}

Distribution of sample by criteria of sex

\begin{tabular}{|l|c|c|}
\hline sex & frequency & percentage \\
\hline male & 9 & 45 \\
\hline female & 11 & 55 \\
\hline
\end{tabular}

Distribution of sample by criteria of total number of days of stay

\begin{tabular}{|l|c|c|}
\hline days & frequency & percentage \\
\hline $10-15$ & 5 & 25 \\
\hline $16-20$ & 8 & 40 \\
\hline $21-25$ & 5 & 25 \\
\hline $25-30$ & 2 & 10 \\
\hline
\end{tabular}

Distribution of sample by criteria of side of the fracture

\begin{tabular}{|l|c|c|}
\hline side & frequency & percentage \\
\hline left & 8 & 40 \\
\hline right & 12 & 60 \\
\hline
\end{tabular}

Distribution of sample by criteria of Mode of Injury

\begin{tabular}{|l|c|c|}
\hline Mode of injury & frequency & percentage \\
\hline fall & 10 & 50 \\
\hline RTA & 10 & 50 \\
\hline
\end{tabular}

\section{Distribution of sample by criteria of fracture classification}

\begin{tabular}{|l|c|c|}
\hline FC & frequency & percentage \\
\hline Type A & 1 & 5 \\
\hline Type B1 & 13 & 65 \\
\hline Type B2 & 4 & 20 \\
\hline Type C1 & 2 & 10 \\
\hline Type C2 & 0 & 0 \\
\hline
\end{tabular}

\section{Distribution of sample by criteria of associated} injuries

\begin{tabular}{|l|c|c|}
\hline Associated injuries & frequency & percentage \\
\hline none & 11 & 47.82 \\
\hline Tendon injury & 4 & 17.39 \\
\hline Other fractures of foot & 8 & 34.78 \\
\hline Compartment syndrome & 0 & 0 \\
\hline
\end{tabular}

Distribution of sample by criteria of comorbidities

\begin{tabular}{|l|c|c|}
\hline Co-morbidities & frequency & percentage \\
\hline None & 11 & 55 \\
\hline diabetes & 2 & 10 \\
\hline hypertension & 3 & 15 \\
\hline $\begin{array}{l}\text { Chronic obstructive pulmonary } \\
\text { disease }\end{array}$ & 0 & 0 \\
\hline Chronic renal failure & 0 & 0 \\
\hline Diabetes and hypertension & 4 & 20 \\
\hline
\end{tabular}

Distribution of sample by criteria of Early post operative complication

\begin{tabular}{|l|c|c|}
\hline EPOC & frequency & percentage \\
\hline none & 20 & 100 \\
\hline Compartment syndrome & 0 & 0 \\
\hline infection & 0 & 0 \\
\hline
\end{tabular}

Distribution of sample by criteria of late post operative complication.

\begin{tabular}{|l|c|c|}
\hline LPOC & frequency & percentage \\
\hline None & 15 & 75 \\
\hline Delayed union or malunion & 0 & 0 \\
\hline Implant failure & 0 & 0 \\
\hline Secondary osteoarthritis & 5 & 25 \\
\hline Deformity & 0 & 0 \\
\hline
\end{tabular}


Distribution of sample by criteria of pain

\begin{tabular}{|l|c|c|}
\hline Pain & Frequency & Percentage \\
\hline None & 14 & 70 \\
\hline mild & 6 & 30 \\
\hline moderate & 0 & 0 \\
\hline severe & 0 & 0 \\
\hline
\end{tabular}

\section{Distribution of sample by criteria of activity} and use of support

\begin{tabular}{|l|c|c|}
\hline $\begin{array}{l}\text { Activity limitation, Use of } \\
\text { support }\end{array}$ & Frequency & Percentage \\
\hline none & 4 & 20 \\
\hline $\begin{array}{l}\text { limited recreational activities,no } \\
\text { support }\end{array}$ & 14 & 70 \\
\hline $\begin{array}{l}\text { limited recreational activities, } \\
\text { cane }\end{array}$ & 2 & 10 \\
\hline $\begin{array}{l}\text { severe limitation of daily and } \\
\text { recreational activities, walker, } \\
\text { crutches, wheelchair }\end{array}$ & 0 & 0 \\
\hline
\end{tabular}

\section{Distribution of sample by criteria of walking} distance

\begin{tabular}{|l|c|c|}
\hline Walking distance & Frequency & Percentage \\
\hline More than 6 blocks & 4 & 20 \\
\hline 4-6 blocks & 14 & 70 \\
\hline 1-3 blocks & 2 & 10 \\
\hline Less than 1 block & 0 & 0 \\
\hline
\end{tabular}

\section{Distribution of sample by criteria of gait} abnormality

\begin{tabular}{|l|c|c|}
\hline & Frequency & Percentage \\
\hline None,slight & 18 & 90 \\
\hline Obvious & 2 & 10 \\
\hline marked & 0 & 0 \\
\hline
\end{tabular}

\section{Distribution of Sample by criteria of ability to} walk on surfaces

\begin{tabular}{|l|c|c|}
\hline Walking surfaces & Frequency & Percentage \\
\hline No difficulty on any surface & 4 & 20 \\
\hline $\begin{array}{l}\text { Some difficulty on uneven } \\
\text { terrains, stairs ,inclines,ladders }\end{array}$ & 16 & 80 \\
\hline $\begin{array}{l}\text { Severe difficulty on uneven } \\
\text { terrains, stairs,inclines,ladders }\end{array}$ & 0 & 0 \\
\hline
\end{tabular}

\section{Distribution of sample by criteria of footwear requirements}

\begin{tabular}{|l|c|c|}
\hline Footwear requirements & Frequency & Percentage \\
\hline Chappals & 18 & 90 \\
\hline Comfort footwear & 2 & 10 \\
\hline Modified shoes or brace & 0 & 0 \\
\hline
\end{tabular}

Distribution of sample by criteria of alignment

\begin{tabular}{|l|c|c|}
\hline Alignment & Frequency & Percentage \\
\hline $\begin{array}{l}\text { Good, plantigrade foot,midfoot } \\
\text { well aligned }\end{array}$ & 20 & 100 \\
\hline $\begin{array}{l}\text { Fair, plantigrade foot, some } \\
\text { degree midfoot } \\
\text { malalignment of observed, no } \\
\text { symptoms }\end{array}$ & 0 & 0 \\
\hline $\begin{array}{l}\text { Poor, nonplantigrade foot, } \\
\text { severe malalignment, } \\
\text { symptoms }\end{array}$ & 0 & 0 \\
\hline
\end{tabular}

\section{Distribution of sample by criteria of functional} outcome

\begin{tabular}{|l|c|c|}
\hline AOFAS score & Frequency & Percentage \\
\hline Excellent & 4 & 20 \\
\hline Good & 11 & 55 \\
\hline Fair & 3 & 15 \\
\hline Poor & 2 & 10 \\
\hline
\end{tabular}

\section{Discussion}

In the present study the average age for males was 29.7 and for females it was 40.2. A study done by Teng AL et al in 2002 had an average age of 40.1 years which is higher for Indian standards ${ }^{[2]}$. Another study by Pereira CJ et al showed a mean age of 31.53 years that is comparable to our result $^{[3]}$.

Females predominated the study at 55\% and right side was found to be more involved in $60 \%$ of the cases.

Average stay in the hospital was 17 days.

High energy injury like RTA had equal incidence as low energy injury like falls from small height. In the study by Pereira CJ et al in 2008 high energy injury especially RTA was the main mechanism of injury. $65 \%$ cases came under Type B2 of Myerson's classification ${ }^{[3]}$.

Four cases had associated tendon injury while 8 cases had other fractures of foot.

Diabetes and hypertension was present in 4 cases while 2 cases had diabetes only and another 3 cases were associated with systemic hypertension. No other comorbidities was noticed.

In our study no early post operative complications was seen. Late post operative complications of which only osteoarthritis was seen in 5 cases. In a case series by Jeifreys, reported that osteoarthritis is almost inevitable sequelae of Lisfranc injury ${ }^{[4]}$. 


\begin{tabular}{|l|c|c|c|c|c|c|c|}
\hline & No. & RTA & $\begin{array}{c}\text { Pre-op } \\
\text { compln }\end{array}$ & $\begin{array}{c}\text { Post-op } \\
\text { pain }\end{array}$ & $\begin{array}{c}\text { Post-op } \\
\text { compln }\end{array}$ & Deformity & AOFAS \\
\hline Jeifreys T et al (1963) & 22 & 9 & - & - & 8 & - & - \\
\hline Kuo R S et al (2000) & 48 & 20 & 2 & - & 12 & - & 80.2 \\
\hline Yuen J S et al (2001) & 11 & - & 1 & 2 & 2 & - & - \\
\hline Pereira CJ et al(2008) & 19 & 7 & - & - & 8 & 5 & 77.53 \\
\hline Present study & 20 & 10 & - & 6 & 5 & - & 80.4 \\
\hline
\end{tabular}

The patients were assessed for functional outcome based on parameters given for calculating AOFAS score, maximum score being 100 points. Most of the patients were pain free after 3 weeks. $10 \%$ of the cases had to use cane for walking. Majority of the cases were able to walk 4-6 blocks and only $10 \%$ had obvious gait abnormality but walking on uneven surfaces and climbing stairs was slightly difficult for $80 \%$ of the cases. $90 \%$ of the cases could walk with chappals and only 2 cases needed footwear modification.

Based on these parameters the AOFAS score was calculated for the cases and the mean score was 80.4 at 6 months .A mean score of 77.53 was reported in the study by Pereira CJ et al $(2008)^{[3]}$. Almost similar results were obtained in study by KuoRS et al (2000), Yuen JS et al (2001), Ruan YP et al $(2011)^{[5,6,7]}$. Most of our patients were happy with the treatment and could continue on with their daily activities.

\section{Conclusion}

We have done a prospective study for finding out the functional outcome of internal fixation in Lisfranc fractures in 20 patients over a period of 18 months from January 2016 to July 2017 in the Department of Orthopedics Govt. Medical College Hospital, Thrissur.

All the patients who came with Lisfranc fractures were admitted to the ward, clinical, hematological and radiological workups were done. Fracture was fixed with screws and kirchner wires. Patients were discharged after suture removal around post op day10 and regularly followed up for 6 months. Non-weight bearing was adviced before discharge from the hospital on below knee cast. Partial weight bearing was started after onset of radiological union and full weight bearing was started after achieving radiological union.
Functional outcome was measured after six months using American Foot and Ankle Society (AOFAS) score and final results were obtained. The results of the study are good and are comparable with other studies in the literature review. No implant related complications were observed during the study.

Following conclusions are drawn from the study.

1) Good anatomic reduction led to improved functional outcome.

2) Transarticular screw fixation provides a stable configuration.

3) Restoration of the arch of foot avoids footwear modification

\section{References}

1. Schildhauer. T.A, Coulibaly M.O, Hoffmann M.F, Fractures and dislocations of the midfoot and forefoot In: CourtBrown, Charles, Heckman. J.D, Mcqueen. M.M, Ricci W.M, Tornetta.P, Rockwood and Green's Fractures in Adults, Eighth edition, Vol 1, NewYork, Wolter Kluwer, 2015 p.2714-19

2. Teng AL et al ,Functional outcome post Lisfranc injury: Transarticular screws, Dorsal bridge plating or combination treatment, J Orthop Trauma, 2017 Aug;31(8):447-452

3. Pereira CJ et al ,Evaluation of Surgical treatment of Lisfranc joint fracture dislocation, Acta Orthop Bras,2008; 16(2):93-97

4. Jeifreys $\mathrm{T}$ et al, Lisfranc fracture dislocation: a clinical and experimental study of tarsometatarsal dislocation and fracture dislocation, $\mathrm{J}$ Bone Joint $\operatorname{Surg}\{\mathrm{Br}\}, 1963 ; 45: 546-51$ 
5. Kuo RS et al ,Outcome after open reduction and internal fixation of Lisfranc joint injuries, J Bone Joint Surg Am, 2000 Nov;82A(11) : 1609-18

6. Yuen JS et al, Open reduction and temporary rigid internal fixation of Lisfranc fracture dislocation ,Singapore Med J, 2001 Jun;42(6): 255-8.

7. Ruan YP et al, Evaluation of surgical treatment of Lisfranc injuries, Zhongguo Gu Shong,2011 Feb; 24(2) :167-9. 